\title{
BMJ Open Observational cross-sectional study on Symptoms Associated to Moisture DAmage at Workplace: the SAMDAW study protocol
}

\author{
Pia Nynäs, ${ }^{\oplus, 2}$ Sarkku Vilpas,, ${ }^{3,4}$ Elina Kankare, ${ }^{3,4}$ Jussi Karjalainen, ${ }^{4,5}$ \\ Lauri Lehtimäki, ${ }^{4,5}$ Jura Numminen, ${ }^{4,5}$ Antti Tikkakoski, ${ }^{4,6}$ Leenamaija Kleemola, ${ }^{4}$ \\ Jukka Uitti ${ }^{1,4}$
}

To cite: Nynäs P, Vilpas S, Kankare $\mathrm{E}$, et al. Observational cross-sectional study on Symptoms Associated to Moisture DAmage at Workplace: the SAMDAW study protocol. BMJ Open 2019;9:e026485. doi:10.1136/ bmjopen-2018-026485

- Prepublication history for this paper is available online. To view these files, please visit the journal online (http://dx.doi org/10.1136/bmjopen-2018026485).

Received 4 September 2018 Revised 6 June 2019 Accepted 7 June 2019
Check for updates

\section{(c) Author(s) (or their} employer(s)) 2019. Re-use permitted under CC BY-NC. No commercial re-use. See rights and permissions. Published by BMJ.

For numbered affiliations see end of article.

Correspondence to

Dr Pia Nynäs; pia.nynas@ttl.fi

\section{ABSTRACT}

Introduction Moisture damage (MD) exposure at work has been shown to increase the risk of new onset asthma and exacerbation of asthma. However, most of the studies in this field have been questionnaire studies. A small proportion of MD-exposed workers are diagnosed with asthma. Many patients with MD exposure at work referred to secondary healthcare report intermittent hoarseness, loss of voice or difficulty to inhale, referring to functional or organic problems of the larynx. For accurate treatment, proper differential diagnostics is paramount. We present an ongoing observational study in which we describe the prevalence of respiratory, voice and other symptoms related to MD at work in patients referred to secondary healthcare. Casecontrol setting will be used to evaluate the frequencies of the background factors, bronchial hyperreactivity and laryngeal findings.

Methods and analysis The study sample consists of patients with workplace MD exposure and associated respiratory tract and/or voice symptoms referred to Tampere University Hospital. The clinical tests conducted to the study patients included comprehensive lung function tests, laboratory and skin prick tests, imaging and clinical evaluation by specialists of respiratory medicine, oto-rhinolaryngology and phoniatrics. The exposure assessment was performed by an occupational physician. The study patients filled out a questionnaire on previous illnesses and other background factors, which for comparison was also sent to 1500 Finnish-speaking people in the same hospital district randomly selected by the Finnish Population Information System. To explore how common laryngeal disorders and voice symptoms are in general, a part of the tests will be conducted to 50 asymptomatic volunteers.

Ethics and dissemination The regional ethics committee of Tampere University Hospital approved the study. All study subjects gave their written informed consent, which is required also from the controls. The results will be communicated locally and internationally as conference papers and journal articles.

\section{INTRODUCTION}

Indoor air quality problems are considered important risk factors for health problems worldwide. ${ }^{1}$ Indoor air-associated symptoms
Strengths and limitations of this study

- This kind of comprehensive clinical study associated with moisture damage exposure at work has not been conducted before.

- This study will increase the understanding of respiratory tract and voice symptoms and associated clinical findings in subjects exposed to moisture damage.

- Information on moisture damage exposure at work is based on documents from the workplace.

- Limitation of a cross-sectional study like this is that it is not possible to obtain information on causal relationships between exposure and symptoms or illnesses.

may be interrelated with different indoor air factors such as insufficient ventilation, ${ }^{2}$ unfavourable temperature conditions, ${ }^{3}$ dry indoor air, ${ }^{4}$ dustiness, ${ }^{5}$ moisture damage (MD) ${ }^{1}$ volatile organic compounds (VOC) ${ }^{6}$ and man-made mineral/vitreous fibres (MMMF/ MMVF). ${ }^{7}$ Even if we do not know the cause of symptoms, ${ }^{1} \mathrm{MD}$ exposure at work has been shown to increase the risk of new onset asthma and exacerbation of asthma. ${ }^{89}$ Other illnesses or respiratory symptoms that have been associated with MD exposure include cough, wheezing, dyspnoea, rhinitis and upper respiratory tract symptoms. ${ }^{910}$

In Finland, located in subarctic area, MDs in residences and schools are common. ${ }^{11}$ Workers in office buildings commonly report symptoms and complaints associated with indoor air. ${ }^{12} 13$ There is also a growing public concern over MDs in buildings and their possible permanent effects on dwellers' or workers' health in Finland, even if there is minor evidence of serious or permanent illnesses other than asthma caused by exposure to MD. ${ }^{914}$ 
There are few studies describing the clinical findings in patients having symptoms when exposed to MD at work. ${ }^{15}{ }^{16}$ Previous studies in this field have mainly been epidemiological, ${ }^{9}$ and most is known about children's risk of developing symptoms in homes or schools with MD. ${ }^{17} 18$ In majority of the studies, the assessment of exposure to MD or presence of symptoms or illnesses has been based on questionnaires. ${ }^{19}{ }^{20}$ Furthermore, only a small proportion of MD-exposed workers are diagnosed with asthma. ${ }^{8}$ According to our clinical experience, many patients with work-related MD exposure and referred to secondary healthcare report intermittent hoarseness, loss of voice or difficulty to inhale, which would refer to functional or organic problems of the larynx. ${ }^{21}$ In the case of laryngeal disorders, asthma medication is not useful or may even worsen the symptoms if the larynx is sensitive to irritation. ${ }^{22}$ Coexisting with asthma, laryngeal disorders may be the cause of insufficient response to asthma treatment.

Studies over the past decades have provided important information on idiopathic environmental intolerance (IEI), in which a person has symptoms from different organ systems when in contact with an environmental factor that does not cause symptoms to most people. ${ }^{2324}$ In odour or multiple chemical sensitivity (MCS), a person reacts with symptoms in association with low levels of airborne chemicals that most people tolerate without problems. ${ }^{25}{ }^{26}$ It seems that some proportion of the patients who have indoor air-associated symptoms in fact have IEI/MCS, but the frequency of this condition among these patients is not known. ${ }^{27}$

As a conclusion, there is a need for a clinical study on patients exposed to MD at workplace focusing especially on differential diagnostics between asthma and laryngeal symptoms, evidence of exposure to MDs and other indoor air risk factors and chemical sensitivity.

\section{Aims of the study}

In patients referred to secondary healthcare because of respiratory tract and/or voice symptoms associated to MD exposure at work, the aims are to

1. Describe the prevalence of different characteristics, symptoms and clinical test findings.

2. Find out the frequency of laryngeal symptoms and their possible influence on asthma diagnostics.

3. Explore the number of patients who fulfil the criteria of chemical sensitivity according to Quick Environmental Exposure and Sensitivity Inventory $\left(\right.$ QEESI) ${ }^{\odot}$ question series. ${ }^{28}$

4. Find out if there are connections between abovementioned symptoms and clinical findings and if it would be possible to allocate the clinical tests according to patient's symptoms in secondary healthcare.

\section{METHODS AND ANALYSIS}

The study is conducted at Tampere University Hospital, which is a secondary level referral centre for a population of 530000 and a tertiary level referral centre for a
Box 1 The criteria on which moisture damage (MD) at workplace was suspected. ${ }^{13}$

1. Indoor air perceived as mouldy or stuffy or otherwise unpleasant.

2. Signs of MDs: visible mould, moisture spots, discolouration of surface materials, disengaging or blistering of flooring materials, crumbling of wall plastering, water leakages through ceilings (buckets on the floors), loose water on surfaces.

3. Renovations because of MDs previously made in the building.

4. Information on MD findings from employer or occupational and health safety personnel.

population of about 1 million people. Patients referred to departments of Occupational Medicine or Phoniatrics or Allergy Centre because of symptoms associated with indoor complaints at their workplace were interviewed as possible study subjects between October 2015 and June 2017. The study inclusion criteria were as follows: (1) age between 18 and 65 years, (2) upper and/or lower respiratory tract and/or voice symptoms, (3) symptoms associated to workplace and (4) at least a strong suspicion of $\mathrm{MD}$ at the workplace (box 1). The exclusion criteria were as follows: (1) severe illness (eg, cancer) and (2) pregnancy. The study design is presented in figure 1 . After the study subjects had given their informed signed consent, the work-associated symptoms were collected by a structured interview. If the patient was not sure if the symptom

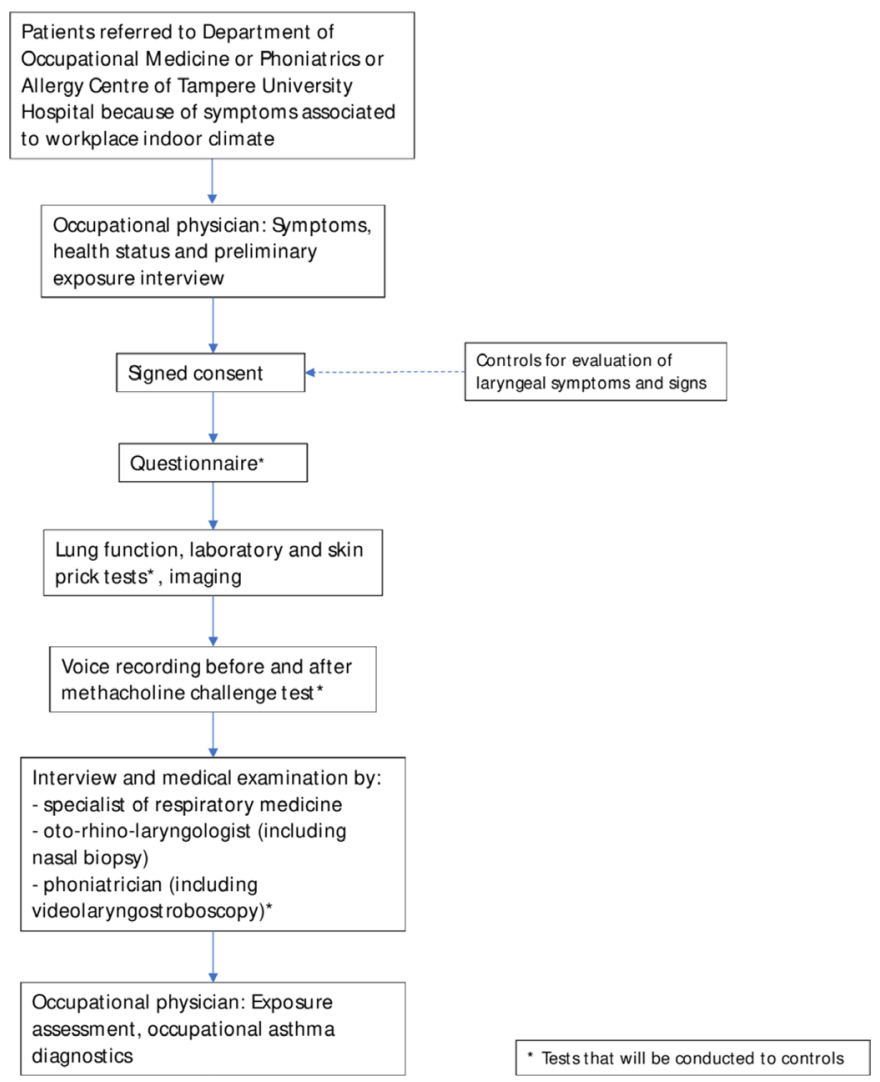

Figure 1 The study design on symptoms associated to moisture damage at workplace. 
Table 1 The clinical tests conducted to the study patients

Lung function tests Two-week serial PEF monitoring, PEF monitoring at and off work, spirometry with bronchodilation test, methacholine challenge test, exhaled nitric oxide $\left(\mathrm{FE}_{\mathrm{NO}}\right)$, diffusing capacity of the lungs

\begin{tabular}{ll} 
Laboratory tests & $\begin{array}{l}\text { Sedimentation rate, C-reactive } \\
\text { protein, blood count, serum total IgE, } \\
\text { serum allergen-specific IgE (different } \\
\text { fungi and storage mites Acarus Siro, } \\
\text { Lepidoglyphus Destructor, Tyrophagus } \\
\text { putrescentiae) }\end{array}$ \\
Skin prick tests & $\begin{array}{l}\text { Birch, timothy, mugwort, horse, dog, } \\
\text { cat, Dermatophagoides Pteronyssinus } \\
\text { house dust mite, latex, aspergillus } \\
\text { fumigatus, storage mites Acarus Siro, } \\
\text { Lepidoglyphus Destructor, Tyrophagus } \\
\text { putrescentiae } \\
\text { Chest x-ray, cone beam CT of the } \\
\text { paranasal sinuses }\end{array}$ \\
\hline
\end{tabular}

PEF, peak expiratory flow.

was more frequent at work, it was not considered to be work associated.

The conducted clinical tests are presented in table 1. According to Finnish asthma guideline, ${ }^{29}$ diagnosis of asthma must be confirmed with a demonstration of variable airway obstruction in lung function measurements: (1) peak expiratory flow (PEF) monitoring, (2) spirometry with bronchodilation test or (3) test for bronchial hyperreactivity (table 2). To confirm or rule out the asthma diagnosis, the patients carried out a 2-week PEF monitoring, spirometry with bronchodilation test and methacholine challenge test. The PEF monitoring included PEF measurements with Pinnacle peak flow metre for 2 weeks in the morning and evening before and after inhaled bronchodilator $(0.4 \mathrm{mg}$ salbutamol).

Table 2 The criteria based on which asthma is diagnosed in different clinical tests ${ }^{29}$

\begin{tabular}{ll}
\hline Clinical test & Criteria for asthma \\
\hline $\begin{array}{l}\text { Two-week PEF } \\
\text { monitoring }\end{array}$ & $\begin{array}{l}\text { At least three times } \\
\text { At least } 15 \% \text { and } 60 \mathrm{~L} / \mathrm{min} \\
\text { improvements of PEF after } \\
\text { bronchodilator. } \\
\text { Diurnal variation of PEF at least } \\
20 \% \text { and } 60 \mathrm{~L} / \mathrm{min} .\end{array}$ \\
\hline Spirometry & $\begin{array}{l}\text { At least } 200 \mathrm{~mL} \text { and } 12 \% \\
\text { improvement in FEV1 or FVC after } \\
\text { bronchodilator }\end{array}$ \\
\hline $\begin{array}{l}\text { Methacholine challenge } \\
\text { test }\end{array}$ & $\begin{array}{l}\text { Cumulative methacholine dose } \\
\text { drop in FEV1 (PD20FEV1 }<600 \mu g)\end{array}$ \\
\hline
\end{tabular}

FEV1, forced expiratory volume in one second; FVC, forced vital capacity; PEF, peak expiratory flow.
Spirometry was performed according to European Respiratory Society/American Thoracic Society guidelines, ${ }^{30}$ and methacholine challenge test using dosimeter with controlled tidal breathing according to Finnish guidelines. ${ }^{31}$ To investigate if possible asthma is associated with work, the patients performed PEF monitoring at and off work $^{32}$ with Vitalograph PEF/FEV Diary device. Diffusing capacity of the lungs ${ }^{33}$ and exhaled nitric oxide $\left(\mathrm{FE}_{\mathrm{NO}}\right)^{34}$ were determined. Specialists of respiratory medicine (JK and LL), oto-rhino-laryngology (JN) and phoniatrics (SV) examined the patients. For diagnosing laryngeal disorders, videolaryngostroboscopy with either rigid or fibreoptic scope was performed, voice samples were recorded and also inspirograms were recorded before and after methacholine tests. Biopsy of nasal mucosa and a blood sample were taken and preserved for later analyses.

Exposure to MD at work was assessed from the documents of the building and indoor air quality investigations made at the workplace, if available, according to Finnish guidelines. ${ }^{35} \mathrm{~A}$ confirmed $\mathrm{MD}$ is graded into different severity categories, if sufficient information is available. Also, MMMFs, VOCs or problems in ventilation conditions at workplace were assessed if these had been measured.

As a non-responder analysis, of the patients who were invited but who did not take part in the study, age, symptoms, the presence of asthma diagnosis and exposure will be evaluated based on patient records.

To explore how common laryngeal disorders are in general, methacholine challenge test, voice recording, clinical examination by the specialist of phoniatrics including videolaryngostroboscopy, $\mathrm{FE}_{\mathrm{NO}}$ and skin prick tests will be conducted to 50 asymptomatic volunteers adjusted for age and gender. The gathering of the volunteers began in August 2018 and it is our estimation that all the volunteers will be examined by the end of 2019 .

\section{Questionnaire/survey}

The study patients and the volunteers fill out a questionnaire including questions on

Previous diseases, medication and upper and lower respiratory symptoms. ${ }^{36}$

Sinusitis symptoms (Sino-Nasal Outcome Test-22 $2^{37}$ ).

Voice symptoms (Voice Activity and Participation Profile, ${ }^{38}$ Voice Handicap Index, ${ }^{39}$ Voice Disorder Questionnaire ${ }^{40}$ ).

Laryngeal symptoms (Newcastle laryngeal hypersensitivity questionnaire $\left.^{41}\right)$.

Reflux symptoms (Reflux Symptom Index ${ }^{42}$ ).

Depression and anxiety symptoms (General Health Questionnaire GHQ-12 $2^{43}$; Generalised Anxiety Disorder 7-item scale ${ }^{44}$ ).

Psychosocial work load ${ }^{45}$ and stress symptoms. ${ }^{46}$

Chemical sensitivity $\left(\mathrm{QEESI}^{\odot}\right){ }^{28}$

To find out if the study group would have different background characteristics from the overall population, the same questionnaire was sent to 1500 Finnish-speaking people in the same hospital district 
randomly selected by the Finnish Population Information System. The proportions of women and men and different age groups in this comparison material are similar to the study population.

\section{Sample size and power calculation}

We estimated that a sample of 100 patients is enough to clinical deduction of the different characteristics of this patient group.

Concerning the population-based comparison material, our aim was to get 400 questionnaire answers (ratio 1:4) to increase the statistical power. Taking recent rather low survey response rates into account, we sent the questionnaire to 1500 people.

To assess if findings suggesting laryngeal disorders are more frequent among those who have respiratory tract or voice symptoms associated to workplace MD, data on frequency of laryngeal findings of asymptomatic people are needed. When analysing the findings of methacholine challenge test of 30 patients, signs of laryngeal disorders were found in $62.5 \%$. We estimated that among $<30 \%$ of asymptomatic people there are such findings in the methacholine challenge test. In power calculation based on findings in the methacholine challenge test, the number of asymptomatic people tested would be 50 with $80 \%$ force and $90 \%$ CI.

\section{Data analyses}

We will analyse descriptive statistics (mean, median or proportion depending on the variable type and distribution) for variables such as gender distribution and age of the patients and their lines of business. We will also analyse the frequencies of different symptoms the patients complain and how these are related to objective findings in different organ systems or new diagnoses of, for example, asthma or laryngeal dysfunction. We will describe the proportions of patients with significant findings in medical assessment at different specialities (ENT, pulmonary and phoniatrics). We will compare frequencies and intensities of different symptoms and clinical findings between the patients and symptomless controls. We will also compare different background factors of the study patients, such as perceived psychosocial work load, with controls of the population who answered to the same questionnaire as the study patients. Dichotomous variables between two groups (patients vs controls or among patients with or without a certain finding) will be compared using $\chi 2$ test and Fisher's exact test, while continuous variables between two groups will be analysed by t-test or Mann-Whitney test depending on the distributions. Multiple logistic regression will be used to assess independent predictors of certain clinical findings among the patients. Based on the relationship between symptoms and different objective findings, we aim to find 'clinical triggers' (certain sets of symptoms) that should prompt clinicians to refer patients to certain specialities.

\section{Patient and public involvement}

Patients or public were not involved in the design of the study. The study patients have received the results of their own tests, explanations for them and necessary treatment.

\section{ETHICS AND DISSEMINATION}

The regional ethics committee of Tampere University Hospital has approved the study (R14095). All study subjects gave their written informed consent, which is required also from the volunteers. The study adheres to good clinical research guidelines and the Helsinki Declaration. $^{47}$

The results will be communicated locally as well as internationally as conference papers and journal articles.

\section{Author affiliations}

${ }^{1}$ Department of Occupational Medicine, Finnish Institute of Occupational Health, Tampere, Finland

${ }^{2}$ Department of Occupational Medicine, Tampere University Hospital, Tampere, Finland

${ }^{3}$ Department of Phoniatrics, Tampere University Hospital, Tampere, Finland

${ }^{4}$ Faculty of Medicine and Health Technology, Tampere University, Tampere, Finland

${ }^{5}$ Allergy Centre, Tampere University Hospital, Tampere, Finland

${ }^{6}$ Department of Clinical Physiology, Tampere University Hospital, Tampere, Finland

Contributors $\mathrm{JU}$ is the head of the study group and PN is the principal researcher. All the writers took part in developing the study protocol: JU and PN planning the exposure assessment; JK, LL and AT the lung function diagnostics measures; JN the diagnostics of upper airways and SV, LK and EK the laryngeal investigations. All authors contributed to and approved the manuscript.

Funding This work was supported by the Tampere Tuberculosis Foundation and the Competitive State Research Financing of the Expert Responsibility area of Tampere University Hospital (grant number 9T069).

Competing interests The study group report grants from Tampere Tuberculosis Foundation, grants from Competitive State Research Financing of the Expert Responsibility area of Tampere University Hospital, during the conduct of the study.

Patient consent for publication Not required.

Ethics approval The regional ethics committee of Tampere University Hospital has approved the study (R14095).

Provenance and peer review Not commissioned; externally peer reviewed.

Open access This is an open access article distributed in accordance with the Creative Commons Attribution Non Commercial (CC BY-NC 4.0) license, which permits others to distribute, remix, adapt, build upon this work non-commercially, and license their derivative works on different terms, provided the original work is properly cited, appropriate credit is given, any changes made indicated, and the use is non-commercial. See: http://creativecommons.org/licenses/by-nc/4.0/.

\section{REFERENCES}

1. WHO. WHO Guidelines for indoor air quality: dampness and mould. Copenhagen: WHO Regional Office for Europe, 2009. http://www. euro.who.int/_data/assets/pdf_file/0017/43325/E92645.pdf.

2. Muscatiello N, McCarthy A, Kielb C, et al. Classroom conditions and $\mathrm{CO} 2$ concentrations and teacher health symptom reporting in 10 New York State Schools. Indoor Air 2015;25:157-67.

3. Skyberg K, Skulberg KR, Eduard W, et al. Symptoms prevalence among office employees and associations to building characteristics. Indoor Air 2003;13:246-52.

4. Wolkoff P. Indoor air humidity, air quality, and health - An overview. Int J Hyg Environ Health 2018;221:376-90.

5. Schneider T. Dust and fibers as a cause of indoor environment problems. Scand J Work Environ Heal Suppl 2008;4:10-17.

6. Salonen H, Pasanen AL, Lappalainen S, et al. Volatile organic compounds and formaldehyde as explaining factors for sensory irritation in office environments. J Occup Environ Hyg 2009;6:239-47. 
7. Salonen HJ, Lappalainen SK, Riuttala HM, et al. Man-made vitreous fibers in office buildings in the Helsinki area. J Occup Environ Hyg 2009;6:624-31

8. Karvala K, Toskala E, Luukkonen R, et al. Prolonged exposure to damp and moldy workplaces and new-onset asthma. Int Arch Occup Environ Health 2011;84:713-21.

9. Mendell MJ, Mirer AG, Cheung K, et al. Respiratory and allergic health effects of dampness, mold, and dampness-related agents: a review of the epidemiologic evidence. Environ Health Perspect 2011;119:748-56.

10. Jaakkola JJ, Hwang BF, Jaakkola MS. Home dampness and molds as determinants of allergic rhinitis in childhood: a 6-year, populationbased cohort study. Am J Epidemiol 2010;172:451-9.

11. Täubel M, Karvonen AM, Reponen T, et al. Application of the Environmental Relative Moldiness Index in Finland. Appl Environ Microbiol 2016;82:578-84.

12. Reijula K, Sundman-Digert C, Reijula K. Assessment of indoor air problems at work with a questionnaire. Occup Environ Med 2004;61:33-8.

13. Ministry of Social Affairs and Health F. Moisture Damages in Workplaces. Memo of the Working Group on Moisture Damages (in Finnish). Helsinki, 2009.

14. Hurraß J, Heinzow B, Aurbach $U$, et al. Medical diagnostics for indoor mold exposure. Int J Hyg Environ Health 2017;220:305-28.

15. White SK, Cox-Ganser JM, Benaise LG, et al. Work-related peak flow and asthma symptoms in a damp building. Occup Med 2013;63:287-90.

16. Hellgren UM, Hyvärinen M, Holopainen $\mathrm{R}$, et al. Perceived indoor air quality, air-related symptoms and ventilation in Finnish hospitals. Int J Occup Med Environ Health 2011;24:48-56.

17. Karvonen AM, Hyvärinen A, Korppi M, et al. Moisture damage and asthma: a birth cohort study. Pediatrics 2015;135:e598-606.

18. Borràs-Santos $A$, Jacobs JH, Täubel M, et al. Dampness and mould in schools and respiratory symptoms in children: the HITEA study. Occup Environ Med 2013;70:681-7.

19. Kim JL, Henneberger PK, Lohman S, et al. Impact of occupational exposures on exacerbation of asthma: a population-based asthma cohort study. BMC Pulm Med 2016;16:148.

20. Kurth L, Virji MA, Storey E, et al. Current asthma and asthma-like symptoms among workers at a Veterans Administration Medical Center. Int J Hyg Environ Health 2017;220:1325-32.

21. Moscato G, Pala G, Cullinan P, et al. EAACI Position Paper on assessment of cough in the workplace. Allergy 2014;69:292-304.

22. Idrees M, FitzGerald JM. Vocal cord dysfunction in bronchial asthma A review article. J Asthma 2015;52:327-35.

23. Genuis SJ. Chemical sensitivity: pathophysiology or pathopsychology? Clin Ther 2013;35:572-7.

24. Rossi S, Pitidis A. Multiple Chemical Sensitivity: Review of the State of the Art in Epidemiology, Diagnosis, and Future Perspectives. $J$ Occup Environ Med 2018;60:138-46.

25. Dantoft TM, Andersson L, Nordin S, et al. Chemical intolerance. Curr Rheumatol Rev 2015;11:167-84.

26. Andersson L, Claeson AS, Dantoft TM, et al. Chemosensory perception, symptoms and autonomic responses during chemical exposure in multiple chemical sensitivity. Int Arch Occup Environ Health 2016;89:79-88.

27. Karvala K, Sainio M, Palmquist E, et al. Building-Related Environmental Intolerance and Associated Health in the General Population. Int J Environ Res Public Health 2018;15:2047.
28. Miller CS, Prihoda TJ. The Environmental Exposure and Sensitivity Inventory (EESI): a standardized approach for measuring chemical intolerances for research and clinical applications. Toxicol Ind Health 1999;15:370-85.

29. Haahtela T, Lehtimäki L, Ahonen E, et al. [Update on current care guidelines: asthma]. Duodecim 2013;129:994-5.

30. Miller MR, Hankinson J, Brusasco V, et al. Standardisation of spirometry. Eur Respir J 2005;26:319-38.

31. Nieminen MM, Lahdensuo A, Kellomaeki L, et al. Methacholine bronchial challenge using a dosimeter with controlled tidal breathing. Thorax 1988;43:896-900.

32. Burge PS. Use of serial measurements of peak flow in the diagnosis of occupational asthma. Occup Med 1993;8:279-94.

33. Macintyre N, Crapo RO, Viegi G, et al. Standardisation of the singlebreath determination of carbon monoxide uptake in the lung. Eur Respir J 2005;26:720-35.

34. Horváth I, Barnes PJ, Loukides S, et al. A European Respiratory Society technical standard: exhaled biomarkers in lung disease. Eur Respir J 2017;49:1600965.

35. Latvala J, Karvala K, Sainio M, et al. Guidelines for Workplace and Occupational Health Actions in Indoor Air Problems (Finnish). Työterveyslaitos 2017 http://www.julkari.fi/handle/10024/132078 (Accessed 20 Aug 2018).

36. Kilpeläinen $\mathrm{M}$, Terho $\mathrm{EO}$, Helenius $\mathrm{H}$, et al. Validation of a new questionnaire on asthma, allergic rhinitis, and conjunctivitis in young adults. Allergy 2001;56:377-84.

37. Morley AD, Sharp HR. A review of sinonasal outcome scoring systems - which is best? Clin Otolaryngol 2006;31:103-9.

38. Sukanen O, Sihvo M, Rorarius E, et al. Voice Activity and Participation Profile (VAPP) in assessing the effects of voice disorders on patients' quality of life: validity and reliability of the Finnish version of VAPP. Logoped Phoniatr Vocol 2007;32:3-8.

39. Alaluusua SJM. Psycho-social handicap of voice disorder and its rehabilitation: a pilot study of Finnish version of Voice Handicap Index [In Finnish] [master thesis], 2003.

40. Sala E, Laine A, Simberg S, et al. The prevalence of voice disorders among day care center teachers compared with nurses: a questionnaire and clinical study. J Voice 2001;15:413-23.

41. Vertigan AE, Bone SL, Gibson PG. Development and validation of the Newcastle laryngeal hypersensitivity questionnaire. Cough 2014;10:1.

42. Belafsky PC, Postma GN, Koufman JA. Validity and reliability of the reflux symptom index (RSI). J Voice 2002;16:274-7.

43. Mäkikangas A, Feldt T, Kinnunen $U$, et al. The factor structure and factorial invariance of the 12-item General Health Questionnaire (GHQ-12) across time: evidence from two community-based samples. Psychol Assess 2006;18:444-51.

44. Spitzer RL, Kroenke K, Williams JB, et al. A brief measure for assessing generalized anxiety disorder: the GAD-7. Arch Intern Med 2006;166:1092.

45. Lahtinen M, Sundman-Digert C, Reijula K. Psychosocial work environment and indoor air problems: a questionnaire as a means of problem diagnosis. Occup Environ Med 2004;61:143-9.

46. Elo AL, Leppänen A, Jahkola A. Validity of a single-item measure of stress symptoms. Scand J Work Environ Health 2003;29:444-51.

47. World Medical Association. World Medical Association Declaration of Helsinki. JAMA 2013;310:2191-4. 